\title{
Protein Immunoprecipitation in Maize
}

María Jazmín Abraham-Juárez*

CONACYT. Molecular Biology Department, Instituto Potosino de Investigación Científica y Tecnológica (IPICYT), San Luis Potosí, SLP, Mexico

*For correspondence: maria.abraham@ipicyt.edu.mx

[Abstract] Protein immunoprecipitation (IP) is a method used to identify cellular protein complexes. Whence, antibodies that specifically recognize a native bait protein or an epitope tag fused to the protein of interest allow the protein of interest to be purified in complexes with other proteins. The extraction buffer must be stringent enough to dissociate weakly-interacting proteins to have a manageable number of proteins for mass spectrometry as well as to increase reproducibility between replicates, but not so stringent than can dissociate all the interactions. So, it is critical to have replicates to can identify reliable candidates to be interacting. As a model plant for grasses, it is important to have reproducible methods to analyze in vivo protein-protein interactions in maize.

Here, I describe a simple and reproducible method for immunoprecipitation of native maize proteins using specific antibodies. This method also has been tested-with excellent results-for IP using magnetic beads coupled to an Anti-GFP antibody. I show the IP of a very low abundant membrane-localized protein called NOD (NARROW ODD DWARF).

Keywords: Maize, Protein purification, Immunoprecipitation, Western blot, Mass spectrometry

\section{Materials and Reagents}

1. Plant tissue ( 3 to $5 \mathrm{~g}$ for ColP and $8 \mathrm{~g}$ for IP to be analyzed by LC-MS/MS)

2. Protease-free $1.5 \mathrm{ml}$ Eppendorf tubes

3. Protease-free $35 \mathrm{ml}$ Sorvall centrifuge tubes

4. Miracloth, pore size: $22-25 \mu \mathrm{m}$ (Merck Millipore, catalog number: 475855)

5. $0.22 \mu \mathrm{m}$ syringe filter, Millex-GP polyethersulfone $33 \mathrm{~mm}$ sterilized (Sigma, catalog number: SLGP033RS)

6. Protease-free pipette tips $(1,000,200$ and $10 \mu \mathrm{l})$

7. $15 \mathrm{ml}$ Falcon tubes

8. $12 \times 12 \mathrm{~cm}$ square Petri dish

9. Liquid nitrogen

10. Tris base (Sigma, catalog number: T1503)

11. Sodium chloride (Sigma, catalog number: S7653)

12. IGEPAL-CA-630 (Sigma, catalog number: I8896)

13. Complete ${ }^{\mathrm{TM}}$ Protease Inhibitor Cocktail tablets (Sigma, catalog number: 11697498001)

14. PhosSTOPTM Phosphatase inhibitor tablets (Sigma, catalog number: 4906845001) 
15. DL-Dithiothreitol (Sigma, catalog number: 43819)

16. Sodium dodecyl sulfate, SDS (Sigma, catalog number: 436143)

17. Bromophenol blue (BIORAD, catalog number: 1610404)

18. Glycerol

19. Polyclonal Anti-NOD produced in Guinea pig (Rosa et al., 2017) (used at 1:2,000 dilution)

20. Polyclonal Anti-Guinea pig HRP-conjugated (used at 1:3,000 dilution) produced in Goat (Thermo Fisher Scientific, catalog number: A18769)

21. Dynabeads M270 Epoxy (Invitrogen, Catalog number: 14301)

22. GelCode Blue Safe protein stain (Thermo Fisher Scientific, catalog number: 24594)

23. Reagents and materials for SDS-PAGE and Western blot (described in Abraham-Juárez, 2019)

24. MQ water

25. Buffer 1 (see Recipes)

26. Buffer 2 (see Recipes)

27. Wash buffer (see Recipes)

28. Elution buffer (see Recipes)

\section{Equipment}

1. Sterile spatula

2. Micropipettes $(1,000,200$ and $10 \mu l)$

3. Sterile mortar and pestle

4. $-80^{\circ} \mathrm{C}$ freezer

5. Refrigerated centrifuge

6. Vortex homogenizer

7. Magnetic separator for $1.5 \mathrm{ml}$ tubes (MagneSphere ${ }^{\circledR}$ Technology Magnetic Separation Stand) (Promega, catalog number: Z5342)

8. Equipment for SDS-PAGE and Western blot

\section{Procedure}

1. Immediately after the plant is sectioned, collect the plant tissue ( 3 to $8 \mathrm{~g}$ ) by freezing it in liquid nitrogen and keep the tissue at $-80^{\circ} \mathrm{C}$ until use.

2. Grind plant material in liquid nitrogen using a mortar and pestle to complete homogeneity. Transfer powder to a $35 \mathrm{ml}$ tube using a spatula that was previously frozen in liquid nitrogen. Complete homogeneity is very important to get a high enough yield for downstream analyses as well as better reproducibility between samples. Be careful not to let the tissue powder thaw before transferring to the $35 \mathrm{ml}$ tube.

3. Mix the ice-cold extraction buffer with the tissue in the $35 \mathrm{ml}$ tube and homogenize immediately using a sterile spatula to avoid degradation. 
Note: Prepare the extraction buffer the same day that it is needed. Keep it on ice until the ground tissue is ready. The volume will depend on the amount of tissue and the number of samples to be processed. $2 x$ volume of plant material $(w / v)$ of extraction buffer is needed.

4. Incubate the homogenate on ice for $30 \mathrm{~min}$; mix by inverting five times every $10 \mathrm{~min}$.

5. Centrifuge the homogenate at $15,000 \times \mathrm{g}$ for $10 \mathrm{~min}$ at $4{ }^{\circ} \mathrm{C}$ twice to clear the protein extract. Before the second spin, change the tube position because it helps pellet deposited debris that sticks to the walls of the tube.

6. Filter the supernatant through two layers of Miracloth into a $15 \mathrm{ml}$ Falcon tube, on ice (Figure 1A). Keep the protein extract on ice until Dynabeads are ready. Take $40 \mu \mathrm{l}$ as the input sample for the SDS-PAGE.

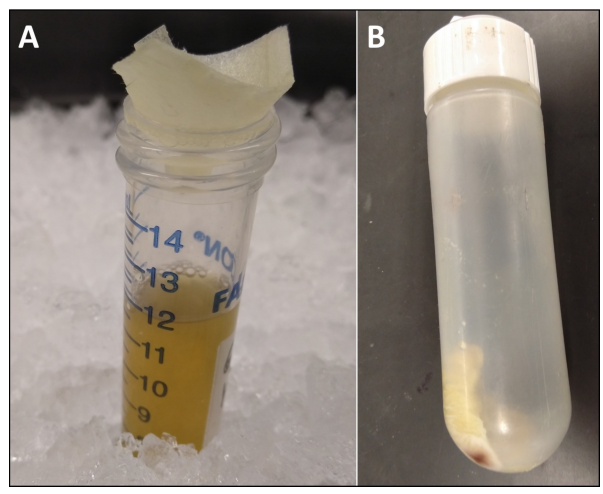

Figure 1. Protein extraction from maize shoot apices. A. Filtering of protein extract through two layers of Miracloth. B. Debris after recovering of protein extract.

7. Place $500 \mu \mathrm{l}$ of Dynabeads (at $10 \mathrm{mg} / \mathrm{ml}$ and coupled covalently to the specific antibody-beadsAb complex), in a $1.5 \mathrm{ml}$ tube and place the tube in the magnetic separator for $1 \mathrm{~min}$. Remove supernatant with a $1 \mathrm{ml}$ pipette tip and then discard it.

Note: The covalent coupling of a specific antibody to magnetic beads (Dynabeads M270 Epoxy) must be carried out according to the manufacturer's instructions. It is advisable to use covalent coupling to prevent contamination of the protein complex elution with heavy and light chains from the antibody. Contamination is detectable by Western blot in the elution, as two strong bands around 50 and $25 \mathrm{kDa}$. Also, commercial antibodies coupled to magnetic beads can be used (e.g., GFP-trap), when transgenic lines expressing tagged proteins of interest are available. If using commercial antibodies-magnetic beads, $40 \mu$ of beads slurry is enough for each sample.

8. Wash the beads-Ab complex with $200 \mu \mathrm{l}$ of wash buffer, by gentle pipetting. Place the tube on the magnet for $1 \mathrm{~min}$, and discard the supernatant. Add $200 \mu \mathrm{l}$ of wash buffer and keep on ice until the protein extract is ready.

9. When the protein extract is ready, place the tube containing beads-Ab complex on the magnet and remove the supernatant. 
10. Add $500 \mu$ of protein extract to the beads-Ab complex and resuspend by gentle pipetting, take the volume with protein extract-beads-Ab and place it in the tube with the complete protein extract volume.

11. Incubate with shaking rotation for $2 \mathrm{~h}$ at $4{ }^{\circ} \mathrm{C}$.

12. Place a $1.5 \mathrm{ml}$ tube on the magnetic separator and fill it with protein extract-beads-Ab homogenate. Leave it to separate for $1 \mathrm{~min}$.

13. Remove the supernatant and keep $40 \mu \mathrm{l}$ for SDS-PAGE (this supernatant is the unbound sample Flow through, FT).

14. Continue separating the FT until complete volume.

15. Wash the beads-Ab-complex four times by adding $200 \mu \mathrm{l}$ of wash buffer each time. For each wash, place the tube in the magnetic separator for $1 \mathrm{~min}$, discarding the supernatant, and then resuspend the beads by gently pipetting with the next wash.

16. In the last wash, transfer the bead suspension to a clean tube after resuspending in wash buffer. This is to avoid co-elution of proteins bound to the tube wall. Keep $40 \mu$ to analyze by SDSPAGE as the Last washing (LW).

17. Elute the protein complexes from the beads by adding $40 \mu \mathrm{l}$ of Elution buffer previously heated at $94{ }^{\circ} \mathrm{C}$ and resuspend by gentle pipetting 10 times. Be careful not to introduce air bubbles.

18. Place the tube in the magnet for $2 \mathrm{~min}$, place the supernatant in a clean tube (this is the immunoprecipitated complex). Discard the beads.

19. Analyze the immunoprecipitated protein complexes by SDS-PAGE followed by Western blot (Abraham-Juárez, 2019) using 1/8 (5 $\mu$ l) of the total elution volume (Figure 2).

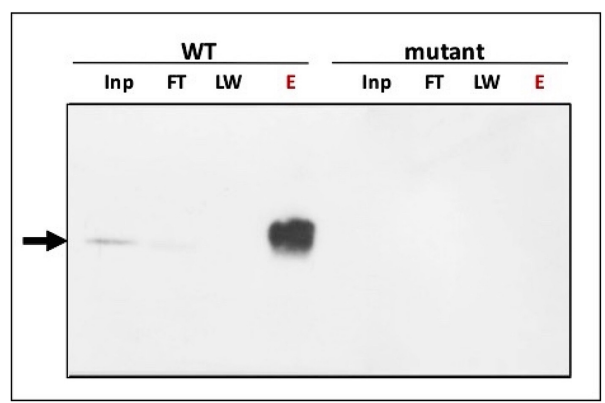

Figure 2. Western blot of the IP using the Anti-NOD antibody. Wild type (WT) and nod-1 mutant tissue were used. The arrow shows the $48 \mathrm{kDa}$ expected band. No signal was detected in the negative control mutant tissue. Exposure time was 2 min using standard ECL substrate. The primary antibody is a polyclonal Anti-NOD produced in Guinea pig (used at 1:2,000 dilution) and the secondary is a polyclonal Anti-Guinea pig HRP-conjugated (used at 1:3,000 dilution) produced in Goat (Thermo Fisher Scientific). Inp: Input protein extract, FT: Flow through or protein not bound, LW: Last washing, E: Elution (IP protein complex).

20. If a strong band with the expected size is detected in the Western blot, run the other $7 / 8$ of sample $(35 \mu \mathrm{l})$ only $2.0 \mathrm{~cm}$ in the SDS-PAGE for mass spectrometry analysis (Figure 3 ). 
21. Separate the gel from the glass support and wash it with $M Q$ water in a new $12 \times 12 \mathrm{~cm}$ square Petri dish for $5 \mathrm{~min}$ twice. Stain with GelCode Blue Safe protein stain for $20 \mathrm{~min}$ and cut the whole gel lane where the band is present (Figure 3B, red rectangle) in $1 \times 1 \times 2 \mathrm{~mm}$ pieces and place them in a low bind protein $1.5 \mathrm{ml}$ tube, all pieces in the same tube for each sample. Keep the gel pieces at $4{ }^{\circ} \mathrm{C}$ until trypsin digestion for mass spectrometry analysis.

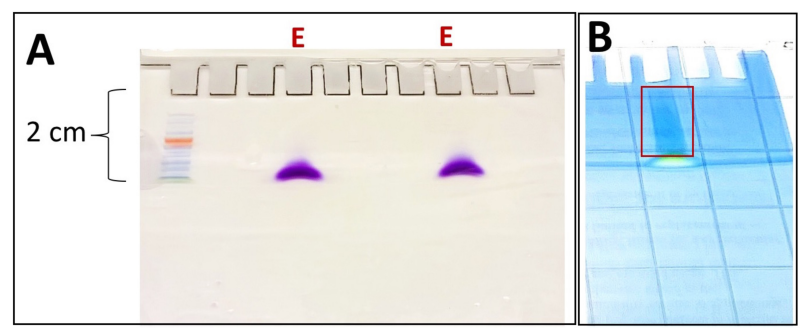

Figure 3. Preparation of IP sample for mass spectrometry analysis. A. Short run gel with 7/8 volume of elution. B. GelCode Blue safe protein staining for $15 \mathrm{~min}$. The red rectangle indicates the cut whole lane.

\section{$\underline{\text { Notes }}$}

1. It is critical to always keep the samples on ice after defrosting. Centrifuge at $4{ }^{\circ} \mathrm{C}$ to avoid protein degradation.

2. Protease inhibitor mix stock is prepared at $25 \mathrm{x}$ by dissolving 1 tablet in $2 \mathrm{ml}$ of $\mathrm{MQ}$ water. Phosphatase inhibitor (PhosSTOP) mix stock is prepared at 10x by dissolving 1 tablet in $1 \mathrm{ml}$ of $\mathrm{MQ}$ water. For use, dilute at $1 \mathrm{x}$ final concentration in the extraction buffer. Stocks may be stored at $-20^{\circ} \mathrm{C}$ for two weeks.

3. After preparation of the sample for mass spectrometry analysis, keep the gel slices at $4{ }^{\circ} \mathrm{C}$ until trypsin digestion. It is stable at $4{ }^{\circ} \mathrm{C}$ for 2 months.

4. For identification of protein complexes, it is very important to have a good negative control. If wild type plants are being used for IP, the ideal negative control is a protein null mutant. In the case of using antibodies against tags (e.g., GFP) the negative control may be a wild type or the mutant affected in the protein of interest.

\section{Recipes}

All of these buffers (Recipes 1-4) are suitable for immunoprecipitation of protein complexes. In general, milder buffer conditions will not dissociate protein-protein interactions. When a protein extract will be analyzed for phosphorylated proteins, add PhosSTOP phosphatase inhibitor mix (1 tablet for $10 \mathrm{ml}$ of final buffer volume).

Note: It is important to prepare all the solutions using MilliQ water, new protease-free tubes and filter the final stock solution through a $0.2 \mu \mathrm{m}$ filter. 
1. Buffer 1

Protein Extraction buffer for proteins dynamically transported between nucleus and cytosol, in native conditions (Tsuda et al., 2017)

$50 \mathrm{mM}$ Tris- $\mathrm{HCl}(\mathrm{pH} 7.5)$

$150 \mathrm{mM} \mathrm{NaCl}$

1\% IGEPAL-CA-630

$2 x$ protease inhibitor mix

2. Buffer 2

Protein Extraction buffer for membrane-localized proteins, in native conditions (modified from Smaczniak et al., 2012)

$50 \mathrm{mM}$ Tris- $\mathrm{HCl}(\mathrm{pH} 7.5)$

$150 \mathrm{mM} \mathrm{NaCl}$

2\% IGEPAL-CA-630

$2 x$ protease inhibitor mix

3. Wash buffer

$50 \mathrm{mM}$ Tris- $\mathrm{HCl}(\mathrm{pH} 7.5)$

$150 \mathrm{mM} \mathrm{NaCl}$

$0.1 \%$ IGEPAL-CA-630 (Sigma)

$1 x$ protease inhibitor mix (Roche)

4. Elution buffer

1x sample loading buffer:

0.05\% Bromophenol blue

\section{$0.1 \mathrm{M}$ DTT}

10\% Glycerol

$2 \%$ SDS

$0.05 \mathrm{M}$ Tris- $\mathrm{HCl} \mathrm{pH} 6.8$

5. $25 x$ Protease inhibitor mix

Dissolve 1 tablet in $2 \mathrm{ml}$ of $\mathrm{MQ}$ water

For use, dilute at $1 \mathrm{x}$ final concentration in the extraction buffer

6. 10x Phosphatase inhibitor (PhosSTOP) mix

Dissolve 1 tablet in $1 \mathrm{ml}$ of MQ water

For use, dilute at $1 x$ final concentration in the extraction buffer

\section{Acknowledgments}

MJAJ was supported by UC-MEXUS CONACYT and by NSF IOS-1238202 at the Dr. Sarah Hake Lab (University of California Berkeley) and by NSF IOS-1652380 at the Dr. Madelaine Bartlett Lab (University of Massachusetts Amherst), where this protocol was developed. I would like to thank Dr. 
Sarah Hake and Dr. Madelaine Bartlett for their continuing scientific support. I declare no conflict of interest regarding the implementation of this protocol.

\section{$\underline{\text { References }}$}

1. Abraham-Juárez, M. J. (2019). Western Blot in Maize. Bio-101: e3257.

2. Rosa, M., Abraham-Juárez, M. J., Lewis, M. W., Fonseca, J. P., Tian, W., Ramirez, V., Luan, S., Pauly, M. and Hake, S. (2017). The maize MID-COMPLEMENTING ACTIVITY homolog CELL NUMBER REGULATOR13/NARROW ODD DWARF coordinates organ growth and tissue patterning. Plant Cell 29(3): 474-490.

3. Smaczniak, C., Li, N., Boeren, S., America, T., van Dongen, W., Goerdayal, S. S., de Vries, Gerco, S., Angenent, C. and Kaufmann, K. (2012). Proteomics-based identification of lowabundance signaling and regulatory protein complexes in native plant tissues. Nat Protoc 7:2144-2158

4. Tsuda, K., Abraham-Juárez, M. J., Maeno, A., Dong, Z., Aromdee, D., Meeley, R., Shiroishi, T., Nonomura, K. I. and Hake, S. (2017). KNOTTED1 cofactors, BLH12 and BLH14, regulate internode patterning and vein anastomosis in maize. Plant Cell 29(5): 1105-1118. 